\title{
Resolution and Pharmacological Analysis of the Voltage-Dependent Calcium Channels of Drosophila Larval Muscles
}

\author{
Michelle L. Gielow, Gang-Guo Gu, and Satpal Singh \\ Department of Biochemical Pharmacology, State University of New York at Buffalo, Buffalo, New York 14260
}

Voltage-dependent calcium channels play a role in many cellular phenomena. Very little is known about $\mathrm{Ca}^{2+}$ channels in Drosophila, especially those in muscles. Existing literature on neuronal $\mathrm{Ca}^{2+}$ channels of Drosophila suggests that their pharmacology may be distinct from that of vertebrate $\mathrm{Ca}^{2+}$ channels. This raises questions on the pharmacology and diversity of $\mathrm{Ca}^{2+}$ channels in Drosophila muscles. Here we show that the $\mathrm{Ca}^{2+}$ channel current in the body-wall muscles of Drosophila larvae consists of two main components. One component is sensitive to 1,4-dihydropyridines and diltiazem, which block vertebrate L-type $\mathrm{Ca}^{2+}$ channels. The second component is sensitive to amiloride, which blocks vertebrate T-type $\mathrm{Ca}^{2+}$ channels.

In contrast to Drosophila brain membrane preparations in which a majority of the $\mathrm{Ca}^{2+}$ channels are phenylalkylamIne-sensitive but dihydropyridine-insensitive, the major current in the muscles was dihydropyridine-sensitive but relatively less sensitive to verapamil. This might indicate an underlying tissue specific distribution of distinct subtypes of dihydropyridine/phenylalkylamine-sensitive $\mathrm{Ca}^{2+}$ channels in Drosophila.

Low verapamil sensitivity of the dihydropyridine-sensitive current of Drosophila muscles also set it apart from the vertebrate L-type channels which are sensitive to 1,4dihydropyridines, benzothiazepines as well as phenylalkylamines. The dihydropyridine-sensitive current in Drosophila muscles activated in a similar voltage range as the vertebrate L-type current. As with the vertebrate current, blockade by dihydropyridines was voltage dependent. Compared to the vertebrate T-type current, the amiloridesensitive current in Drosophila muscles showed higher activation threshold as well as slower inactivation.

These experiments provide the first clear resolution of a Drosophila $\mathrm{Ca}^{2+}$ current into two distinct components. With the previous resolution of the $\mathrm{K}^{+}$current into four components, Drosophila larval muscles now provide one of the few preparations in which the whole cell current can be resolved completely into individual ionic currents. This will help in determining the role of individual currents in cellular excitability and other calcium related processes; in analyzing structure, function, and regulation of specific

Received Dec. 19, 1994; revised Apr. 27, 1995; accepted May 2, 1995

This work was supported by NSF Grant IBN-9011427 to S.S., and an NIH Training Grant and an AFPE Fellowship to M.L.G. We thank Dr. David J. Iriggle for advice and help during this work

Correspondence should be addressed to Dr. Satpal Singh, Department of Biochemical Pharmacology, 308 Hochstetter Hall, State University of New York at Buffalo, Buffalo, NY 14260

Copyright (C) 1995 Society for Neuroscience $\quad 270-6474 / 95 / 156085-09 \$ 05.00 / 0$ types of $\mathrm{Ca}^{2+}$ channels; as well as in understanding the molecular basis of calcium channel diversity.

[Key words: Drosophila, calcium currents, calcium channel blockers, dihydropyridines, verapamil, amiloride, pharmacology, physiology, muscle, larva, insects]

Voltage-dependent calcium channels have been observed in a variety of species. In addition to playing a functional role in many cellular processes (Augustine et al., 1985; Hille, 1992) they provide an entry for essential ions that serve as intracellular messengers. These channels are typically classified into several groups. L-Type channels have a high-voltage threshold for activation (Tsien et al., 1988; Bean, 1989) and are believed to be the dominating $\mathrm{Ca}^{2+}$ channel type in muscle preparations (Bean, 1989). Vertebrate L-type channels are blocked by 1,4-dihydropyridines (DHPs), phenylalkylamines and benzothiazepines, as the $\alpha_{1}$ subunit contains a distinct but allosterically coupled receptor for each class of agents (for review, see Catterall et al., 1988; Hosey and Lazdunski, 1988; Glossmann and Striessnig, 1990; Triggle, 1990). T-type channels are characterized by transient, low voltage-activated currents (Fox et al., 1987) and have also been found in muscle preparations (Bean, 1985; Nilius et al., 1985; Cognard et al., 1986; Yatani et al., 1987). T-Type currents show sensitivity to octanol and flunarizine (Tytgat et al., 1988; Llinas et al., 1989), although these agents are nonselective. Selective T-channel blockade has been shown with amiloride (Tang et al., 1988; Hirano et al., 1989).

Leung and Byerly (1991) recorded single-channel $\mathrm{Ca}^{2+}$ currents from cultured Drosophila embryonic myotubes and neurons. Their studies suggest multiple types of calcium channels in neuronal cells, with fast, complicated kinetics. These channels are generally insensitive to the DHPs, phenylalkylamines, benzothiazepines, and $\omega$-conotoxin GVIA (McCleskey et al., 1987; Byerly and I eung, 1988). They are instead blocked by spider toxins (Plectreurys toxin and Hololena toxin) (Leung et al., 1989). These data raise questions regarding whether calcium channels in Drosophila, and perhaps all insects, are insensitive to the classical calcium channel antagonists used for vertebrate systems. In addition, all $\mathrm{Ca}^{2+}$ channels in Drosophila neurons appear to have a similar voltage dependence of activation (Leung and Byerly, 1991). Comparable results are observed in another invertebrate system, as Aplysia bag neurons also possess different types of $\mathrm{Ca}^{2+}$ channel displaying a similar voltage dependence of activation (Strong et al., 1987).

Reconstitution studies with Drosophila head extracts show both a very high affinity and a low affinity site for phenylalkylamines (Pauron et al., 1987; Greenberg et al., 1989; Pelzer ct al., 1989). Very little specific binding is detected for $(+){ }^{3} \mathbf{H}_{-}$ PN200-110 and $d$-(cis)-3 ${ }^{3}$-diltiazem (Greenberg et al., 1989). 
Phenylalkylamine binding is partially inhibited with diltiazem and is allosterically unaffected by high concentrations of $1,4-$ dihydropyridines. Pelzer et al. (1989) discovered $\mathrm{Ca}^{2+}$ channels in Drosophila brain membranes sensitive to phenylalkylamines alone and distinct channels sensitive to DHPs alone. These results indicate that the protein containing the phenylalkylamine receptor may be distinct from that containing the DHP receptor, giving $\mathrm{Ca}^{2+}$ channels from Drosophila brain membranes unique pharmacological properties.

Differences in pharmacological and physiological properties between $\mathrm{Ca}^{2+}$ channels from vertebrates and those from Drosophila and other invertebrates (Pauron et al., 1987; Greenberg et al., 1989; Pelzer et al., 1989; Gilly and Scheuer, 1993; Brezina et al., 1994; Yamoah and Crow, 1994) raise several interesting questions including those on the evolutionary origin and phylogenetic significance of such differences, on the nature of various drug receptors on ion channels, and on allosteric interactions between these receptors. It is also not clear if the $\mathrm{Ca}^{2+}$ channels of insect muscles show similar differences from vertebrate channels as seen in insect neurons. Of immediate importance are questions directly related to the nature, diversity and pharmacological sensitivity of $\mathrm{Ca}^{2+}$ channels in Drosophila muscle. In this report we resolve the $\mathrm{Ca}^{2+}$ channel current from Drosophila muscles into its components and study the pharmacological sensitivity of these components.

\section{Materials and Methods}

Preparation. Calcium channel currents of larval body-wall muscles (Jan and Jan, 1976; Wu and Haugland, 1985) were studied using the twomicroelectrode voltage-clamp technique. Wandering third instar larvae (Wu and Haugland, 1985; Singh and Wu, 1989) of the wild-type Drosophila melanogaster strain Canton-S were used. Flies were grown on a standard cornmeal medium at $21^{\circ} \mathrm{C}$. The larvae were pinned dorsal side up on a dissection dish and placed under a dissection saline. The cuticle along the dorsal midline was cut and pinned back. All internal organs were removed, allowing a clear preparation of body-wall muscle fibers. Current recordings were obtained from ventro-lateral longitudinal muscle fibers $7,6,13$, and 12 , from abdominal segments $2-6$, excluding cells that endured obvious physical damage.

Electrophysiology. Electrodes were pulled from thin walled, $1.0 \mathrm{~mm}$, borosilicate glass capillaries with filaments (World Precision Instruments, Sarasota, FL.) using a David Kopf Instruments puller, model 750. The voltage electrode was filled with $2.5 \mathrm{M} \mathrm{KCl}$ and the current electrode with a $3: 1$ mixture of $2.5 \mathrm{M} \mathrm{KCl}: 2 \mathrm{M}$ potassium citrate (Singh and Wu, 1989). Resistance of both electrodes was in the range of 10-20 $\mathrm{M} \Omega$

Currents were elicited by $500 \mathrm{msec}$ voltage steps, from a holding potential of $-100 \mathrm{mV}$ or $-30 \mathrm{mV}$ (as stated), to potentials between -60 and $+40 \mathrm{mV}$, in $10 \mathrm{mV}$ increments. Pulses were given at $10 \mathrm{sec}$ intervals. No $\mathrm{Na}^{+}$current is observed in Drosophila muscles (Salkoff and Wyman, 1983; Wu and Haugland, 1985). In general, there has been no direct demonstration of $\mathrm{Na}^{+}$current in insect muscles (Pichon and Ashcroft 1985; Hille, 1992). $\mathrm{K}^{+}$currents were blocked by tetraethylammonium, 4-aminopyridine, and quinidine (Wu and Haugland, 1985; Gho and Mallart, 1986; Singh and $\mathrm{Wu}, 1989$ ). In experiments with 1,4-dihydropyridines, a holding potential of $-30 \mathrm{mV}$ was used, as the effects of these agents are voltage dependent. A slight run-down of current amplitude was observed, but was not significant in early recordings. Therefore, all recordings were made within thirty minutes after the dissection began. The temperature of the recording chamber was maintained at $4^{\circ} \mathrm{C}$ with a peltier junction and measured for each larva with a thermocouple probe.

Solutions. The dissection saline contained (in $\mathrm{mM}$ ): $128 \mathrm{NaCl}, 35.5$ sucrose, $2 \mathrm{KCl}, 5 \mathrm{HEPES}$, and $4 \mathrm{MgCl}_{2}$ at $\mathrm{pH} 7.1$. The current recorded in all experiments was barium current through $\mathrm{Ca}^{2+}$ channels in a $\mathrm{Ca}^{2+}$ free solution. $\mathrm{A} \mathrm{Ca}^{2+}$ free solution helps prevent muscle contraction during recording, prevent activation of the calcium-dependent potassium channels, and prevent calcium-dependent inactivation of the $\mathrm{Ca}^{2+}$ channels. The recording saline contained (in $\mathrm{mM}$ ): $128 \mathrm{NaCl}, 35.5 \mathrm{su}-$ crose, $2 \mathrm{KCl}, 5$ HEPES, 20 tetraethylammonium, 1 4-aminopyridine, $10 \mathrm{BaCl}_{2}, 4 \mathrm{MgCl}_{2}$, and 0.1 quinidine at $\mathrm{pH} 7.1$.

Drugs. ( \pm )Verapamil hydrochloride, diltiazem hydrochloride, amiloride hydrochloride, and nifedipine were obtained from Sigma Chemical Company, St. Louis, MO. Isradipine (PN200-110) and ( \pm )Bay K 8644, generous gifts from Dr. David Triggle (SUNY Buffalo), came respectively from Sandoz (Basel, Switzerland) and Miles Pharmaceuticals (West Haven, CT). All drugs were stored at $-12^{\circ} \mathrm{C}$ in the dark, diluted to their respective desired concentrations immediately before each experiment, and used under minimal light conditions. Dihydropyridines were dissolved in ethanol. The maximum final ethanol concentration used in the experiments was $0.2 \%$. This concentration was without effect on the barium current of control fibers.

Equipment and software. A Macintosh IISi provided the voltageclamp command pulses through a 12 bit digital-to-analog converter using a MacADIOS II/16 board from GW Instruments (Somerville, MA). An Axoclamp 2A amplifier (Axon Instruments, Foster City, CA) or a Turbo TEC 01C/02/03 two-electrode clamp (npi electronic GmbH, Tamm, Germany) was used for recordings. Data were acquired after 16 bit analog-to-digital conversion. Further analysis was performed with a program written in Think-C (Symantec Corporation, Cupertino, CA).

Data handling. The test currents were digitally sampled every 500 $\mu \mathrm{sec}$, except during examination of capacitive transients (Wu and Haugland, 1985), which were sampled every $100 \mu \mathrm{sec}$. Currents were digitally corrected for linear leakage with respect to currents obtained at $-60 \mathrm{mV}$. Current densities, expressed as nanoamperes per nanofarad $(\mathrm{nA} / \mathrm{nF})$, were calculated by dividing the measured current by the capacitance of the cell to avoid differences due to fiber size. All traces show the average of data obtained from a number of fibers as denoted. Current amplitude for each pulse was measured at the peak. The inhibition reported for various pharmacological agents was determined by comparing the peak current amplitude obtained at $0 \mathrm{mV}$. Data are expressed as mean values \pm standard errors of mean (SEM).

\section{Results}

\section{Whole-cell calcium channel currents}

The current recorded with a holding potential of $-100 \mathrm{mV}$ consisted of a transient phase reaching its peak rapidly, and a more sustained phase that persisted with maintained depolarization (Fig. 1A); $100 \mu \mathrm{M} \mathrm{Cd} \mathrm{Cd}^{2+}$ blocked the current, signifying it to be $\mathrm{Ca}^{2+}$ channel current (Fig. $1 B$ ). The current-voltage $(I / V)$ relationship for the current is shown in Figure $1 C$. The maximum current, observed at $0 \mathrm{mV}$, reached a peak of $-18.04 \pm 1.07$ $\mathrm{nA} / \mathrm{nF}(n=15)$.

It is likely that the total $\mathrm{Ca}^{2+}$ channel current seen in Figure 1 might consist of more than one component. One effective method to resolve ionic currents uses differences in the voltage range of activation (Fox et al., 1987; Hille, 1992). For example, the T-type current in vertebrate preparations generally activates at potentials positive to about $-70 \mathrm{mV}$ membrane potential and dominates at potentials negative to $-20 \mathrm{mV}$. The vertebrate L-type current on the other hand generally activates at membrane potentials positive to about $-20 \mathrm{mV}$. Drosophila muscles did not show any $\mathrm{Ca}^{2+}$ current at potentials negative to $-30 \mathrm{mV}$ (Fig. 1C). These results are similar to those from Drosophila embryonic neurons where multiple types of whole-cell calcium currents all activate at potentials above $-40 \mathrm{mV}$ (Byerly and Leung, 1988). Similarly, all subtypes of single $\mathrm{Ca}^{2+}$ channels in Drosophila neurons activate within the same range of potentials and can not be classified by their activation threshold (Leung and Byerly, 1991). If Drosophila muscles also have more than one type of $\mathrm{Ca}^{2+}$ channel with similar thresholds of activation, it would be difficult to distinguish them on such a basis. We therefore relied on pharmacological agents and on differences in inactivation properties to resolve individual currents. 
A

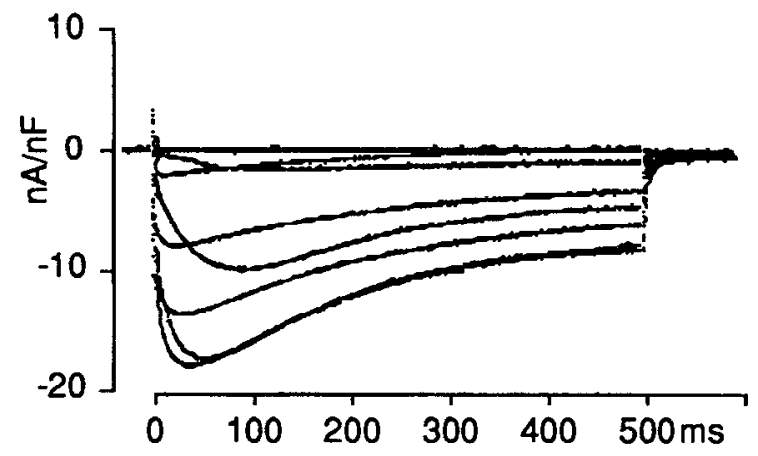

B

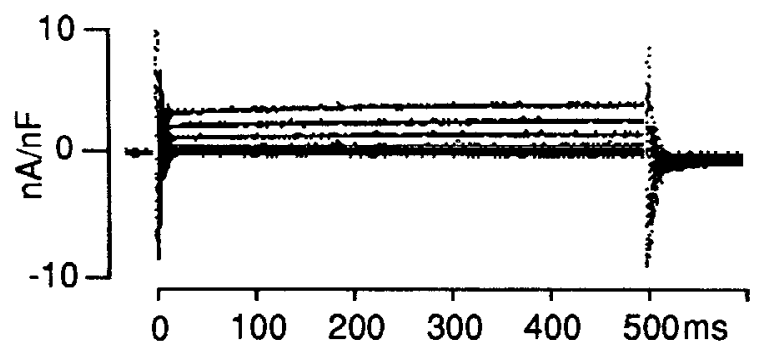

C

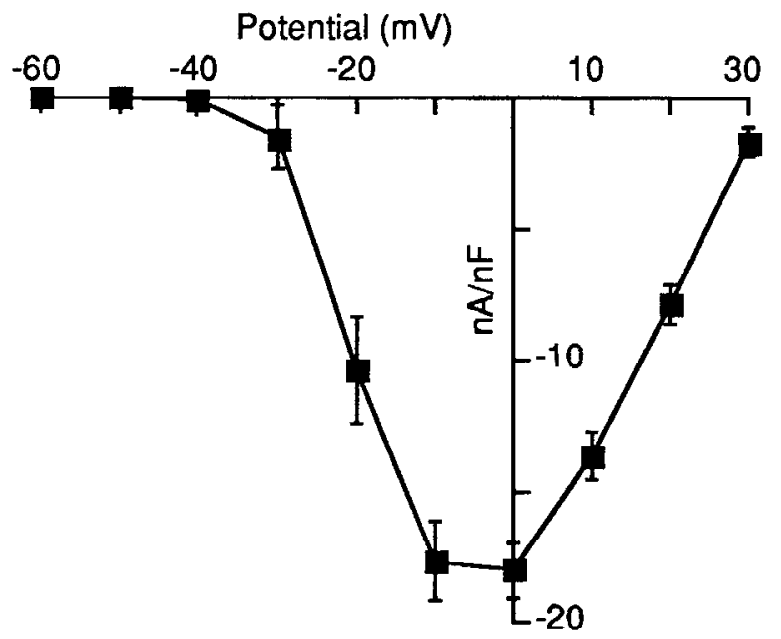

Figure 1. $\mathrm{Ca}^{2+}$ channel currents from larval muscle fibers of Drosophila elicited from a holding potential of $-100 \mathrm{mV}$. A. Traces show leak-subtracted membrane current recordings obtained by $500 \mathrm{msec}$ voltage-clamp pulses from $-60 \mathrm{mV}$ through $+30 \mathrm{mV}$ in $10 \mathrm{mV}$ increments. Unless otherwise mentioned, current traces in all subsequent figures were obtained with the same pulse protocol. $L$ (number of larvae) $=10 ; F$ (number of fibers) $=15 . B$, Blockade of calcium channel currents by $100 \mu \mathrm{M}$ cadmium $(L=3 ; F=9)$. $C$, The current-voltage relationship $(I / V)$ for the peak value of the current. Currents shown in this and subsequent figures were normalized to membrane capacitance to avoid differences due to fiber size.

\section{An amiloride sensitive component of the $\mathrm{Ca}^{2+}$ channel current}

Since the T-type current is prevalent in vertebrate muscles, we wanted to check if a corresponding current contributed to the total $\mathrm{Ca}^{2+}$ channel current in Drosophila muscles. A few agents
A

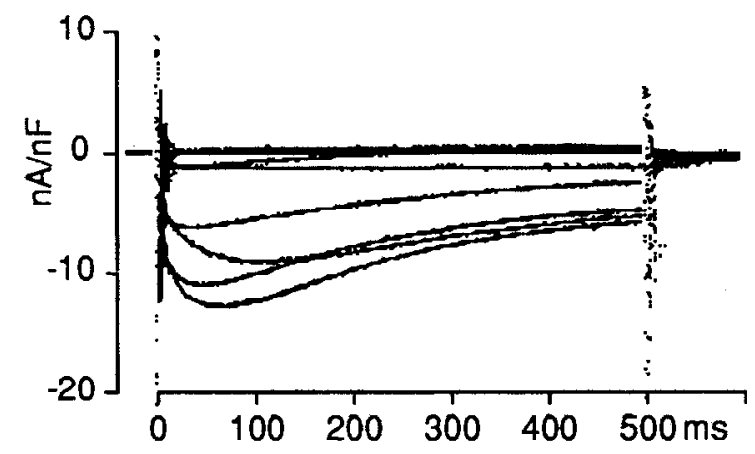

B

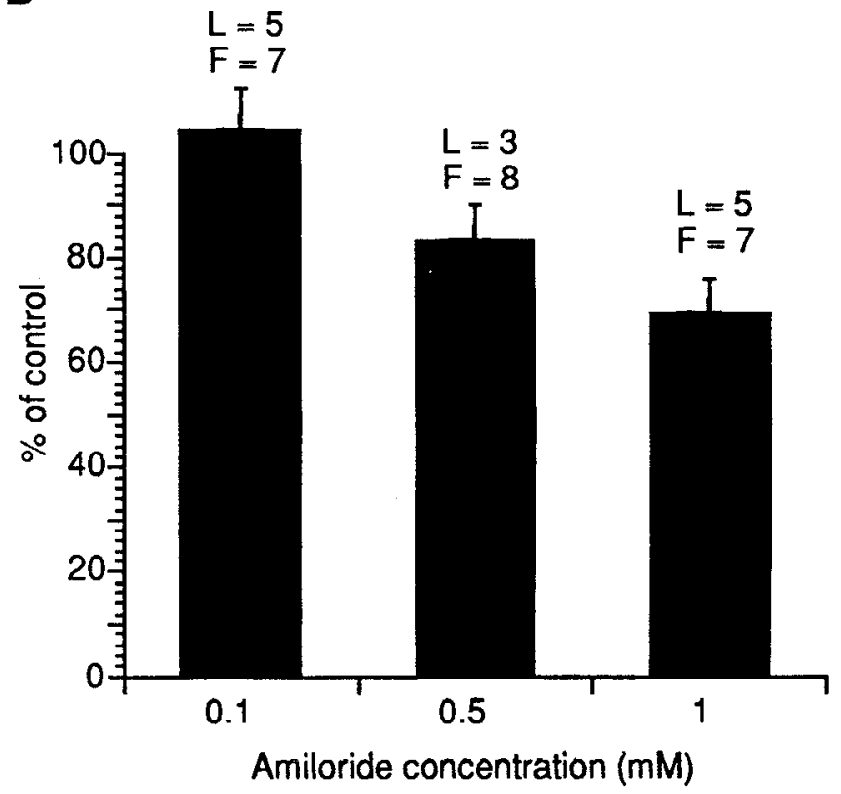

Figure 2. Effect of amiloride on the $\mathrm{Ca}^{2+}$ current. $\mathrm{A}$, Current elicited from a holding potential of $-100 \mathrm{mV}$ in the presence of $1 \mathrm{~mm}$ amiloride. $L=5 ; F=7 . B$, Blockade of the peak current (at $0 \mathrm{mV}$ ) by increasing concentrations of amiloride. At $1 \mathrm{~mm}$, the peak current was inhibited by $31.6 \pm 6.1 \%$.

inhibit T-type channels, although their effects are generally not specific (Tytgat et al., 1988; Llinas et al., 1989). Amiloride is the most selective of the known T-type channel blockers and has been Inost extensively used. It selectively blocks the T-type channels in mouse neuroblastoma, chick DRG neurons (Tang et al., 1988), canine cardiac Purkinje cells (Hirano et al., 1989) and guinea pig ventricular myocytes (Tytgat et al., 1990). In these studies, approximately $1 \mathrm{~mm}$ amiloride produces near total blockade, although incomplete block can be achieved with lower concentrations. Figure $2 A$ shows the currents obtained from Drosophila muscles in the presence of $1 \mathrm{~mm}$ amiloride. On average, $1 \mathrm{~mm}$ amiloride reduced the peak current at $0 \mathrm{mV}$ by 31.1 $\pm 6.1 \%(n=7) . \Lambda$ part of the total $\mathrm{Ca}^{2+}$ channel current in Drosophila muscle fibers is thus similar to the vertebrate T-type current in its sensitivity to amiloride. Figure $2 B$ represents the peak current inhibition with various concentrations of amiloride.

In vertebrates, $\mathrm{T}$-type $\mathrm{Ca}^{2+}$ channels are virtually inactivated at a depolarized holding potential $\left(V_{h}\right)$ such as $-30 \mathrm{mV}$, while L-type channels are not (Fox et al., 1987). Recordings with -30 
A

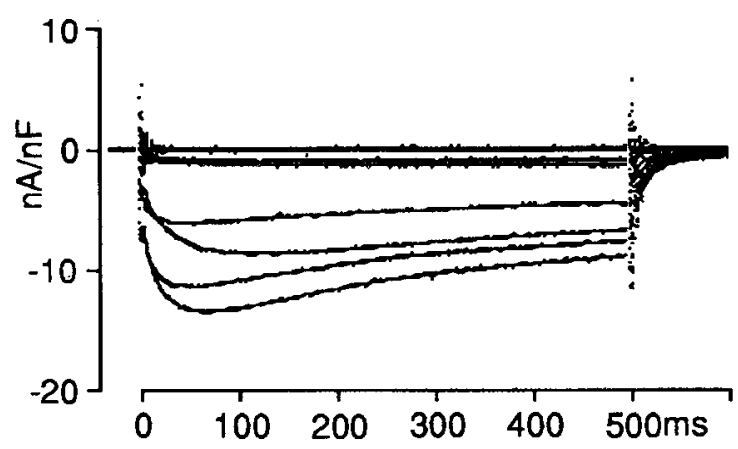

B

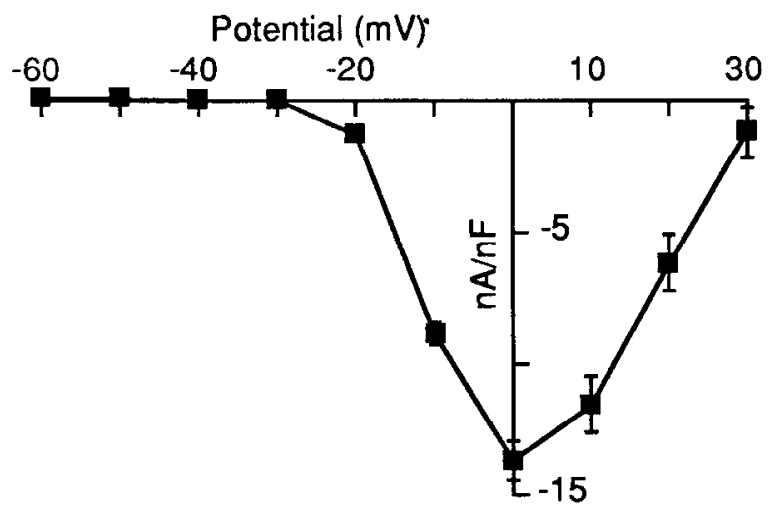

Figure 3. A depolarized holding potential inactivates part of the current. $A, \mathrm{Ca}^{2+}$ channel currents from larval muscle fibers of Drosophila elicited from a depolarized holding potential of $-30 \mathrm{mV}$. $B$, The current-voltage relationship for currents shown in $A . L=9 ; F=12$.

$\mathrm{mV} V_{h}$ were pursued to examine if $\mathrm{Ca}^{2+}$ current in Drosophila inactivated at this $\mathrm{V}_{\mathrm{h}}$. Figure 3 shows the cuments obtained and the corresponding $I / V$ plot. Holding the membrane at $-30 \mathrm{mV}$ decreased the peak current by $23.8 \pm 7.3 \%(n=12)$ compared to $-100 \mathrm{mV}$.

It would be interesting to see if the current component inactivated by $-30 \mathrm{mV} V_{h}$ corresponds either completely or partly to the amiloride-sensitive current. To address this question, we recorded the currents from a holding potential of $-30 \mathrm{mV}$ in the presence of $1 \mathrm{~mm}$ amiloride. If amiloride and depolarized holding potential affect two different components of the total current, amiloride is expected to further reduce the current recorded with a $V_{h}$ of $-30 \mathrm{mV}$. Amiloride did not show such an effect (Fig. 4). This indicates that it is likely to be the amiloridesensitive current that is inactivated at $-30 \mathrm{mV}$. This also indicates that amiloride may act selectively on the current which is inactivated at $-30 \mathrm{mV} V_{h}$ without blocking the noninactivating current.

\section{A dihydropyridine sensitive component of the $\mathrm{Ca}^{2+}$ channel current}

An L-type current, sensitive to 1,4-dihydropyridines (DHPs), forms an important component of many vertebrate cells. To examine if a DHP-sensitive current existed in Drosophila muscle

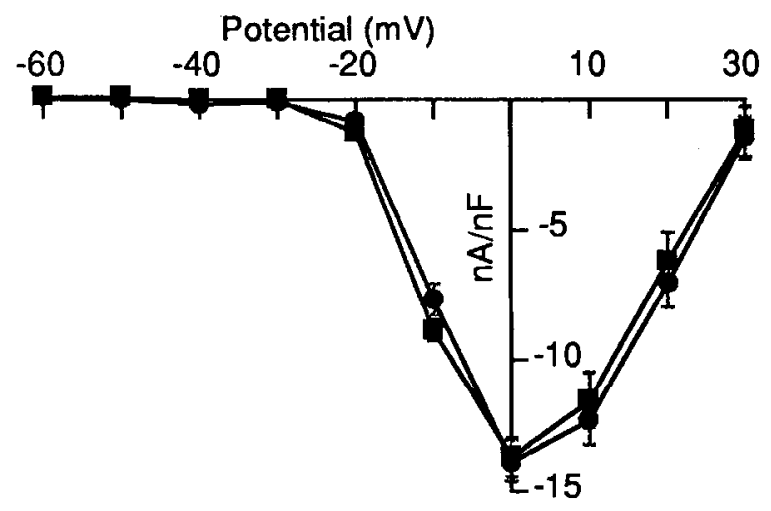

Figure 4. Current-voltage relationship of the effect of amiloride on currents elicited from a holding potential of $-30 \mathrm{mV}$. Both control currents ( $\square: L=9 ; F=12$ ) and currents in the presence of $1 \mathrm{~mm}$ amiloride ( $L=3 ; F=7$ ) were obtained with a holding potential of $-30 \mathrm{mV}$.

fibers, we tested the effect of a DHP antagonist PN200-110. In voltage-clamp experiments, the ability of DHP antagonists to block $\mathrm{Ca}^{2+}$ current is strongly affected by holding potential (Bean, 1984; Sanguinetti and Kass, 1984; Uehara and Hume, 1985). The binding affinity of DHP antagonists increases dramatically in a variety of systems upon membrane depolarization (Kokubun et al., 1986; Greenberg et al., 1989; Wei et al., 1989). The modulated-receptor hypothesis (Hille, 1977) proposes that the affinity of a ligand for its receptor depends on the channel state, which may change with the membrane potential. Depolarization promotes the inactive channel state, increasing the potency of DHP antagonists (Bean, 1984). Therefore, all experiments with $\mathrm{PN} 200-110$ were performed from a holding potential $\left(V_{h}\right)$ of $-30 \mathrm{mV}$, encouraging high affinity binding to its receptor. Note that with a $V_{h}$ of $-30 \mathrm{mV}$, the amiloride-sensitive current is already inactivated. At this $V_{h}$, PN200-110 produced near complete blockade of the current (Fig. 5A), with $10 \mu \mathrm{M}$ PN200110 giving $92.6 \pm 6.4 \%$ blockade $(n=9)$. Experiments with a $V_{h}$ of $-100 \mathrm{mV}$ showed relatively little channel blockade with similar concentrations (data not shown), indicating a voltage dependence of the effects of PN200-110. Figure $5 B$ represents the peak current inhibition seen with various concentrations of PN200-110. It also shows the blockade of the current by $10 \mu \mathrm{M}$ nifedipine and $10 \mu \mathrm{M}$ nitrendipine, two other frequently used dihydropyridine antagonists of the vertebrate L-type current. The data indicate that $50 \%$ current inhibition would require between 1 and $5 \mu \mathrm{M}$ PN200-110. DHP concentrations between 1-10 $\mu \mathrm{M}$ produce L-type $\mathrm{Ca}^{2+}$ channel blockade in frog skeletal muscle (Palade and Almers, 1985; Neuhaus et al., 1990), chick sensory neurons (Fox et al., 1987), guinea pig cardiac cells (Lee and Tsien, 1983; Hess et al., 1984), and human skeletal muscle fibers (Garcia et al., 1992). Since micromolar concentrations of DHP antagonists can sometimes block potassium currents (DeCoursey et al., 1985), another important criterion for identifying vertebrate L-type channels is the action of dihydropyridine agonists such as Bay K 8644. The DHP-sensitive current in Drosophila muscles showed a dramatic increase in the tail currents in response to Bay K 8644 (Fig. 5C). These data suggest that the current elicited from a holding potential of $-30 \mathrm{mV}$ may be mediated through $\mathrm{Ca}^{2+}$ channels which are sensitive to 1,4-dihydropyridines. 
A

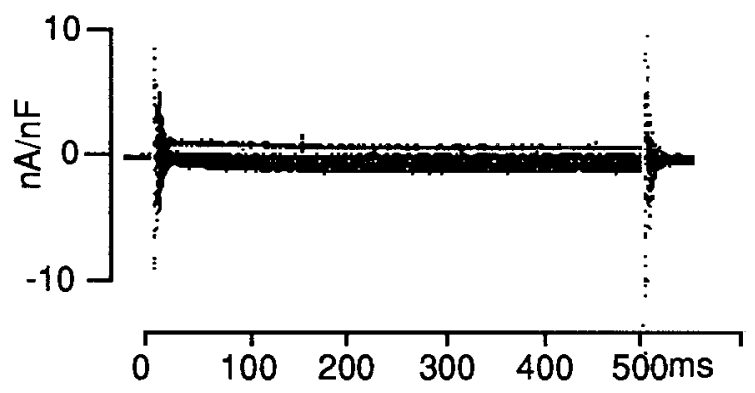

B

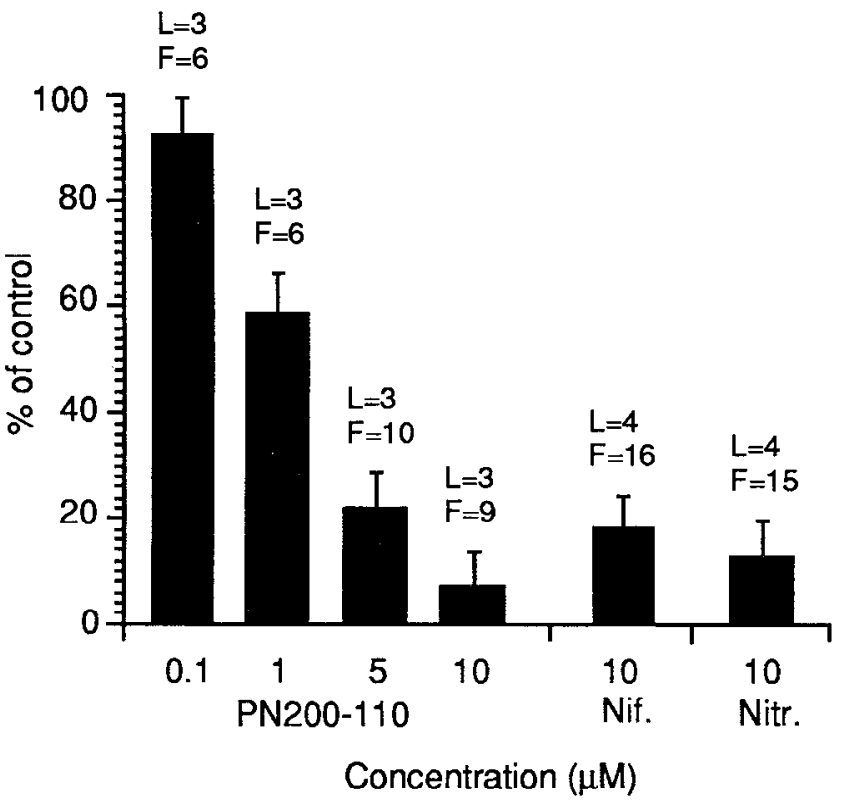

C

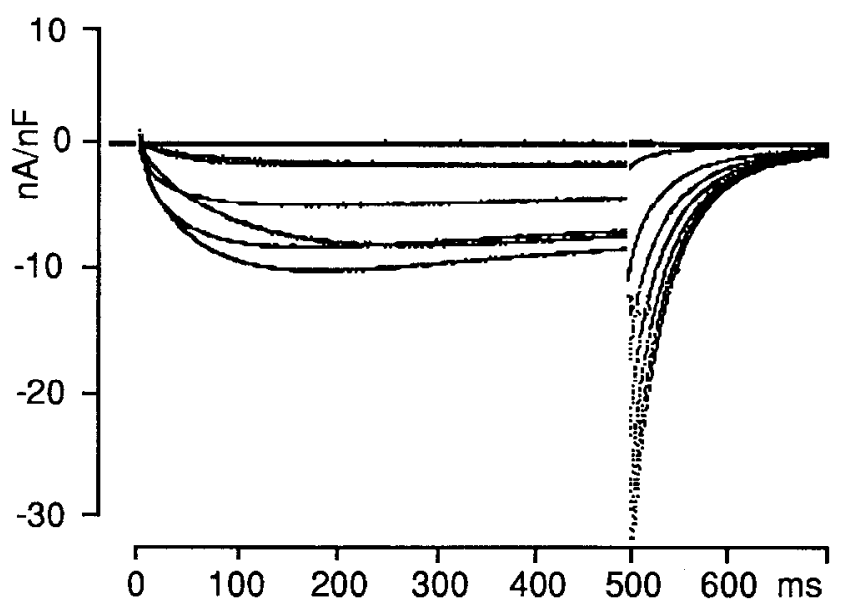

Figure 5. 1,4-Dihydropyridine sensitivity of one component of the $\mathrm{Ca}^{2+}$ current. $A$, Currents recorded from a holding potential of $-30 \mathrm{mV}$ in the presence of $10 \mu \mathrm{M}$ PN200-110. $L=3 ; F=9 . B$, Blockade of the peak current $($ at $0 \mathrm{mV}$ ) by increasing concentrations of PN200-110; by $10 \mu \mathrm{M}$ nifedipine (Nif); and by $10 \mu \mathrm{M}$ nitrendipine (Nitr). At $10 \mu \mathrm{M}$ PN200-110, the peak current was inhibited by $92.6 \pm 6.4 \%$. $C$. Enhancement of tail currents (compare with the tail currents in Fig. $3 A$ ) by $1.0 \mu \mathrm{M}$ Bay K 8644 in recordings made from a holding potential of $-30 \mathrm{mV}(L=4 ; F=14)$.
Effect of verapamil and diltiazem on the 1,4-dihydropyridinesensitive current

Since the vertebrate L-type channels are sensitive to DHPs, phenylalkylamines (e.g., verapamil) as well as benzothiazepines (e.g., diltiazem) (Triggle, 1990) whereas a majority of $\mathrm{Ca}^{2+}$ channels from Drosophila brain membranes are sensitive to verapamil but not to DHPs (Pelzer et al., 1989), it would be very interesting to see if the DHP-sensitive channels from Drosophila muscle are sensitive to verapamil and diltiazem. We examined the effect of these two agents at a holding potential of $-30 \mathrm{mV}$ which isolates the DHP-sensitive current from the amiloridesensitive component.

High concentrations of verapamil were required to block the DHP-sensitive current in Drosophila muscles (Fig. 6A). Figure $6 B$ shows the effect of increasing concentrations of verapamil, with $96.2 \pm 7.4 \%(n=12)$ blockade occurring at $500 \mu \mathrm{M}$ verapamil. The data indicate that $50 \%$ blockade would require between 10 and $100 \mu \mathrm{M}$ verapamil. The major fraction of single channels obtained from brain membrane preparations in Dro sophila show a marked inhibition by $1 \mathrm{nM}(-) \mathrm{D}_{600}$ (Pelzer et al., 1989); 1-15 $\mu \mathrm{M}$ concentrations of phenylalkylamines reduce the L-type channel current in guinea pig cardiac cells (Lee and Tsien, 1983) and frog skeletal muscle (Palade and Almers, 1985). This indicates that the DHP-sensitive channels in the Drosophila muscles may be relatively less sensitive to verapamil than the phenylalkylamine-sensitive channels from Drosuphila brain membranes or the vertebrate L-type channels.

Diltiazem inhibited the current recorded from a holding potential of $-30 \mathrm{mV}$, with $1 \mathrm{mM}$ blocking about $96.0 \pm 4.3 \%$ of the current $(n=16)$ (Fig. $7 A$ ). Figure $7 B$ shows inhibition with increasing diltiazem concentrations. The data indicate that $50 \%$ inhibition would require a little over $100 \mu \mathrm{M}$ diltiazem. For comparison, $50 \mu \mathrm{M}$ diltiazem produces L-type current blockade in guinea pig cardiac cells (Lee and Tsien, 1983) and $500 \mu \mathrm{M}$ diltiazem produces approximately $50 \% \mathrm{Ca}^{2+}$ current blockade in Xenopus oocytes expressing rat skeletal muscle RNA (Dascal et al., 1992).

Five hundred micromolar verapamil blocked about $71.0 \pm$ $7.9 \%$ of the total current recorded with a $V_{h}$ of $-100 \mathrm{mV}(n=$ 15) (Fig. 6C). Similarly, $1 \mathrm{~mm}$ diltiazem blocked about $74.8 \pm$ $8.0 \%$ of the total current elicited from a $V_{h}$ of $-100 \mathrm{mV}(n=$ 16) (Fig. $7 \mathrm{C}$ ). Since the DIIP-sensitive current constitutes approximately $70-75 \%$ of the total current elicited from this holding potential (Figs. 2, 3), verapamil and diltiazem blocked most of this current, as they had done at a $V_{h}$ of $-30 \mathrm{mV}$, without an apparent effect on the amiloride-sensitive current. The data also indicate that the action of verapamil and diltiazem may not depend on the holding membrane potential.

If the total calcium current recorded at a $V_{h}$ of $-100 \mathrm{mV}$ consists primarily of the DHP-sensitive and the amiloride-sensitive current, application of both $1 \mathrm{~mm}$ diltiazem and $1 \mathrm{~mm}$ amiloride should block most of this current. As expected, the two drugs together blocked about $92.1 \pm 5.0 \%$ of the total current $(n=16)$ (Fig. 8$)$.

Resolution of the dihydropyridine-sensitive and the amiloridesensitive current

With the above observations, it becomes easy to resolve the two $\mathrm{Ca}^{2+}$ currents in the larval muscles. The amiloride-sensitive current can be recorded at a holding potential of $-100 \mathrm{mV}$ by blocking the DHP-sensitive current by diltiazem (Fig. 7C). DHP 


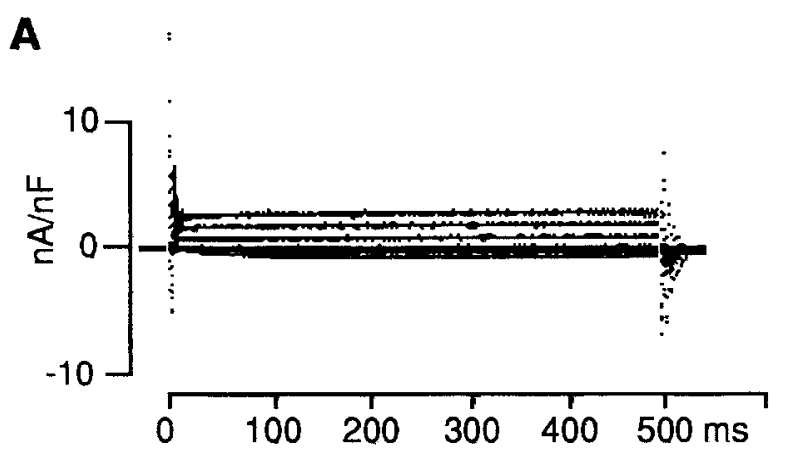

B

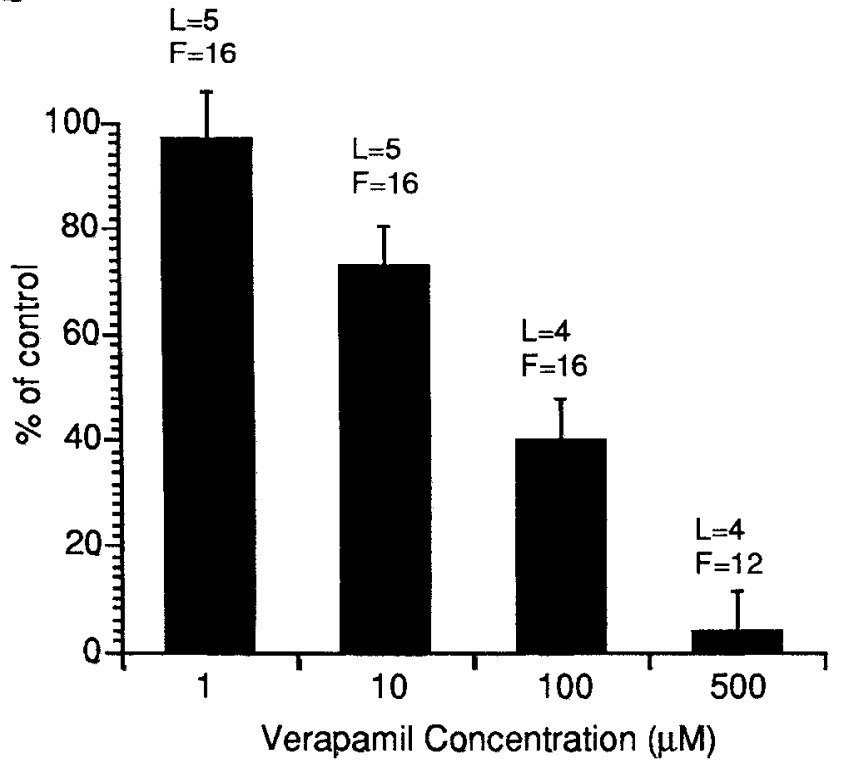

C

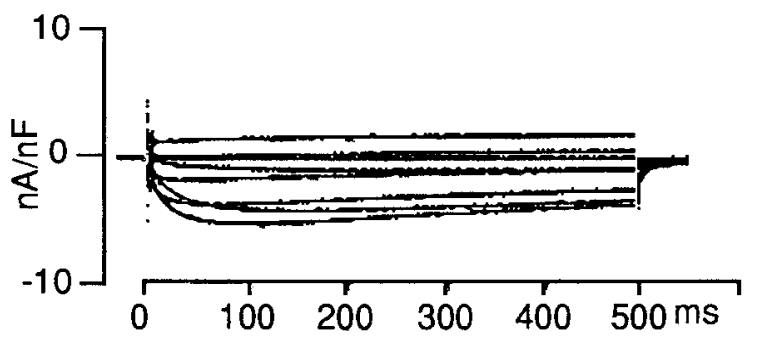

Figure 6. Effect of verapamil on the dihydropyridine-sensitive current. $A$, Currents recorded from a holding potential of $-30 \mathrm{mV}$ in the presence of $500 \mu \mathrm{M}$ verapamil, with pulses up to $+40 \mathrm{mV}$. $B$, Blockade of the peak current (at $0 \mathrm{mV}$ ) by increasing concentrations of verapamil. At $500 \mu \mathrm{M}$ verapamil, the peak current was inhibited by $96.2 \pm 7.4 \%$. $C$, Blockade of the current recorded from a holding potential of -100 $\mathrm{mV}$ by $500 \mu \mathrm{M}$ verapamil. The peak current was inhibited by about $71.0 \pm 7.9 \%$.

blockers can not be used for this purpose because they act only at depolarized potentials at which the amiloride-sensitive current is inactivated. The DHP-sensitive current can be isolated from the amiloride sensitive current either by using $1 \mathrm{~mm}$ amiloride (Fig. $2 A$ ) or by holding the membrane potential at $-30 \mathrm{mV}$ (Fig. 3A).

\section{Discussion}

This report describes currents through the voltage-dependent calcium channels of the body-wall muscles of Drosophila larvae. Measurements revealed two main components of the current, a 1,4 dihydropyridine-sensitive component and an amiloride-sensitive component.

Membrane excitability in the larval body-wall muscles of Drosophila is based on $\mathrm{Ca}^{2+}$ and $\mathrm{K}^{+}$channels. $\mathrm{K}^{+}$channels have been previously resolved into four components, namely $I_{\mathrm{A}}, I_{\mathrm{K}}$, $I_{\mathrm{CF}}$, and $I_{\mathrm{CS}}$ (Singh and Wu 1989, Singh and Wu, 1990). Resolution of the $\mathrm{Ca}^{2+}$ current into two components in the present study thus provides one of the few preparations in which the whole-cell current can be completely resolved into its individual components. This separation of currents will facilitate the analysis of the physiological and pathological roles of each current, as well as greatly aid in the genetic and pharmacological analysis of the individual ion channels and their modulation. Ability to record each of the two $\mathrm{Ca}^{2+}$ current components in isolation from other currents would be helpful in identifying mutations that affect either of these two currents. This would in turn be very useful in undertaking a mutational analysis of the structure, function and regulation of these channels. Analysis of pharmacological and physiological differences between the insect and the vertebrate $\mathrm{Ca}^{2+}$ channels will be useful in designing useful strategies for the control of harmful insects.

As mentioned in the introductory section and Results, earlier literature has revealed pharmacological differences between vertebrate and insect $\mathrm{Ca}^{2+}$ channels and raised questions on the extent of these differences. Our data show an overlap in pharmacological specificity of the L-type and the T type vertebrate currents with the two currents described in this report. Sensitivity to 1,4-dihydropyridines (PN200-110, nifedipine and nitrendipine) and benzothiazepines (diltiazem) is characteristic of the vertebrate L-type $\mathrm{Ca}^{2+}$ current. Amiloride-sensitivity is characteristic of the T-type $\mathrm{Ca}^{2+}$ current in vertebrates. This argues that the pharmacology of insect $\mathrm{Ca}^{2+}$ channels may not be entirely different from that of mammalian channels.

We did not examine detailed physiological properties of the two currents. However some simple observations can be made from the data presented here. The activation threshold of between -30 and $-20 \mathrm{mV}$ for the DHP-sensitive current (Fig. 3B) was comparable to the vertebrate L-type current which starts activating around -30 to $-10 \mathrm{mV}$ (Tsien et al., 1988; Hille, 1992). Almost complete inactivation of the Drosophila amiloride-sensitive current at a holding potential of $-30 \mathrm{mV}$ corresponded to inactivation of the vertebrate T-type current under similar conditions. On the other hand, as mentioned in Results, the activation threshold of $-30 \mathrm{mV}$ for the amiloride-sensitive current was higher than the activation threshold of about -70 to $-50 \mathrm{mV}$ for the vertebrate T-type current (Tsien et al., 1988; Hille, 1992). In addition, the current in Figure $7 C$ does not show a transient nature characteristic of the vertebrate T-type current (Fox et al., 1987). The Drosophila muscle current inactivated by about $22.3 \pm 11.7 \%(n=16)$ of the peak value during a $500 \mathrm{msec}$ pulse to $0 \mathrm{mV}$ (calculated from Fig. $7 \mathrm{C}$ ). On the other hand, the vertebrate T-type current shows rapid inactivation, with a time constant ranging between about 20 and $50 \mathrm{msec}$ (Tsien et al., 1988). These difference are not surprising since physiological properties of invertebrate $\mathrm{Ca}^{2+}$ currents often differ from those of vertebrate $\mathrm{Ca}^{2+}$ currents (Strong et al., 1987; Leung and Byerly, 1991). 
A

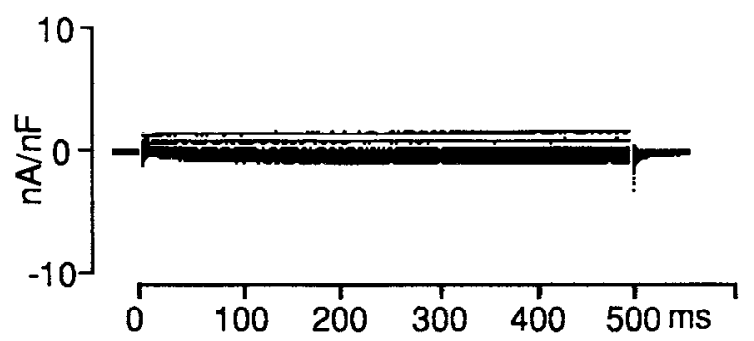

B

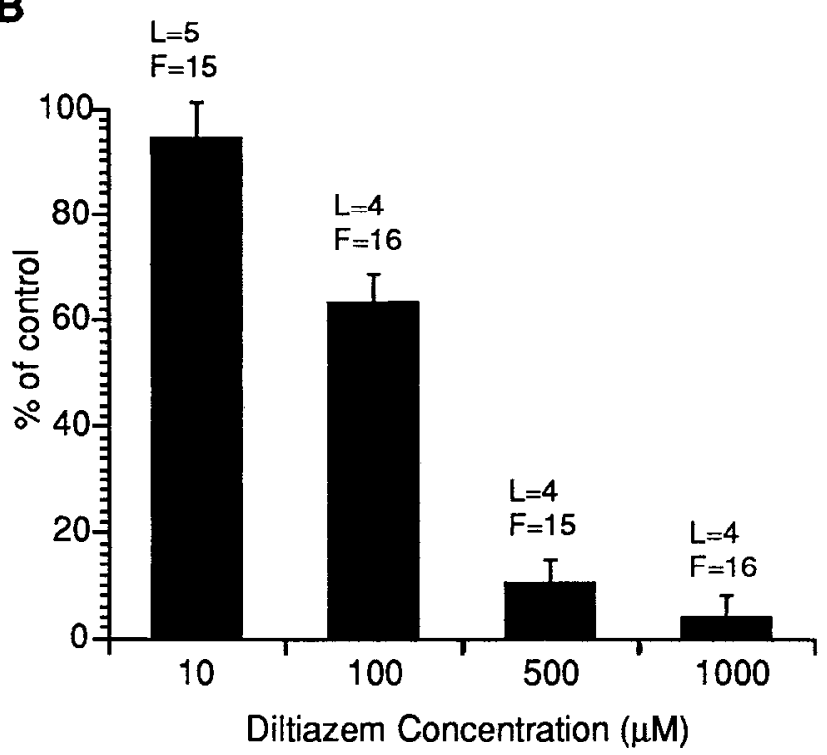

C

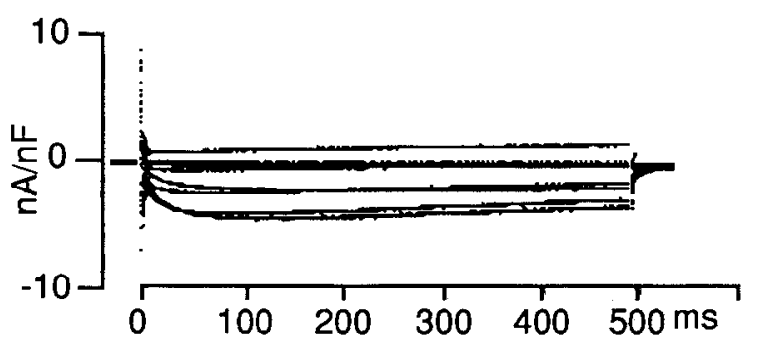

Figure 7. Blockade of the dihydropyridine-sensitive current by diltiazem. $A$, Currents recorded from a holding potential of $-30 \mathrm{mV}$ in the presence of $1 \mathrm{~mm}$ diltiazem, with pulses up to $+40 \mathrm{mV}$. $B$, Blockade of the peak current (at $0 \mathrm{mV}$ ) by increasing concentrations of diltiazem. At $1 \mathrm{~mm}$ diltiazem, the peak current was inhibited by $96.0 \pm 4.3 \%$. $C$, Blockade of the $\mathrm{Ca}^{3+}$ current recorded from a holding potential of -100 $\mathrm{mV}$ by $1 \mathrm{~mm}$ diltiazem. The peak current was inhibited by about 74.8 $\pm 8.0 \%$.

It was suggested in the Results that the current inactivated by a holding potential of $-30 \mathrm{mV}$ is likely to be the same as the amiloride-sensitive current. This interpretation was linked to the lack of amiloride action on the current recorded at the $V_{h}$ of -30 $\mathrm{mV}$. With the current experimental protocol, we cannot rule out the possibility that the action of amiloride may be voltage dependent such that it may not act at a depolarized $V_{h}$ of $-30 \mathrm{mV}$.
A

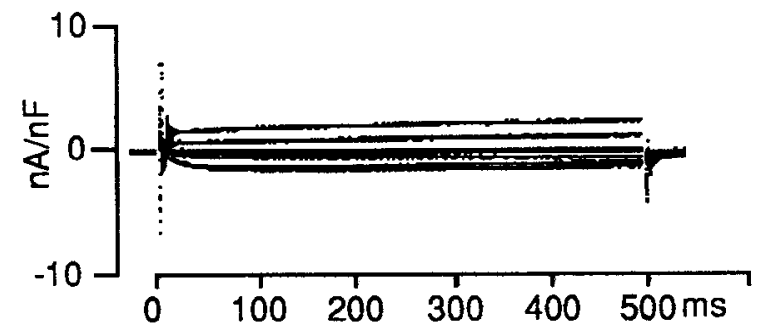

B

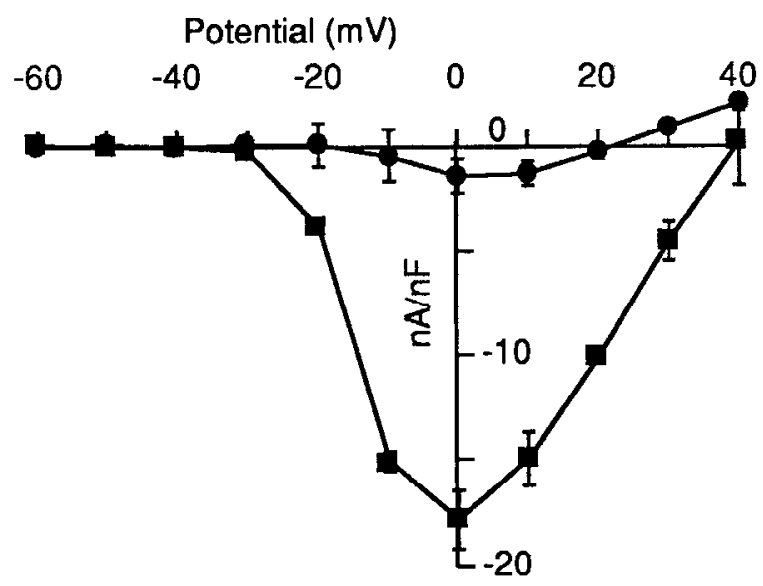

Figure 8. Effect of diltiazem and amiloride together on the total $\mathrm{Ca}^{2+}$ channel current. $A$, Currents recorded from a holding potential of -100 $\mathrm{mV}$ in the presence of $1 \mathrm{~mm}$ diltiazem and $1 \mathrm{~mm}$ amiloride, with pulses up to $+40 \mathrm{mV} . B$, Current-voltage relationship for the currents recorded in the presence $(L=4 ; F=16$ ) or absence $(\mathbb{a}: L=5 ; F=17)$ of $1 \mathrm{~mm}$ diltiazem plus $1 \mathrm{~mm}$ amiloride.

However, another line of argument supports the likely overlap between the amiloride-sensitive current and the current inactivated at a $V_{h}$ of $-30 \mathrm{mV}$. Experiments with diltiazem and amiloride indicate that the total $\mathrm{Ca}^{2+}$ current recorded from a $V_{h}$ of $-100 \mathrm{mV}$ consists primarily of the DHP-sensitive and the amiloride sensitive components (Fig. 8). An almost complete blockade of the noninactivating component at a holding potential of $-30 \mathrm{mV}$ by diltiazem argues that the amiloride-sensitive current has likely been inactivated at this holding potential.

Our data raise several interesting questions on the pharmacology of the dihydropyridine/phenylalkylaninue-sensitive $\mathrm{Ca}^{2+}$ channels. Previous single-channel studies on brain membrane preparations of Drosophila show that most channels are sensitive to phenylalkylamines but insensitive to DHPs, while a small fraction are sensitive to DHPs, but insensitive to phenylalkylamines (Pelzer et al., 1989). Thus, a particular channel molecule is proposed to have a binding site for either verapamil or DHPs, but not both. This is in contrast to the vertebrate L-type channels which not only bind DHPs, phenylalkylamines and benzothiazepines on the same subunit, but also show allosteric interactions between the three binding sites (for review, see Catterall et al., 1988; Hosey and Lazdunski, 1988; Glossmann and Striessnig, 1990; Triggle, 1990). The major component of the whole-cell $\mathrm{Ca}^{2+}$ current from Drosophila muscles, in the present study, was blocked by PN200-110 and diltiazem but showed low sensitivity to verapamil. It will be interesting to examine the pharmacology 
of single channels from these muscles and ask if individual channels have receptors for both DHPs and benzothiazepines and if these receptors show allosteric interactions as they do in vertebrate L-type channels. It will also be interesting to see if diltiazem affects either of the two Drosophila neuronal $\mathrm{Ca}^{2+}$ channel subtypes, the ones that show DIIP sensitivity and the ones that show phenylalkylamine sensitivity (Pelzer et al., 1989). Distribution of various subtypes of dihydropyridine/phenylalkylamine-sensitive $\mathrm{Ca}^{2+}$ channels appear tissue specific, with neurons showing predominantly phenylalkylamine-sensitive channels and muscles showing a predominantly 1,4-dihydropyridine-sensitive current. With a rapid increase in our knowledge of the diversity of various subtypes of channels and their tissuespecific expression, it will be interesting to see if all muscles express one subtype and all neurons another subtype of channels, or if there are differences among various muscles or various populations of neurons. The muscle currents shown here were recorded from larvae, whereas brain membrane preparations in previous reports were made from adult flies. The observed differences may also be related to a difference in the developmental stage. Differential splicing may also play some role in the diversity and the tissuc-specific expression of various subtypes of currents. Another very interesting aspect to examine would be the evolutionary relationship between the vertebrate and the insect $\mathrm{Ca}^{2+}$ channels on one hand, and between the neuronal and the muscle $\mathrm{Ca}^{2+}$ channels in Drosophila on the other. Further studies, some involving single-channel analysis, are needed to answer many of these questions.

All recordings in our experiments were made within thirty minutes of the start of the dissection. The currents displayed evidence of "rundown" with time after the dissection, but current reduction was quite minimal within the first 30 min. Rundown of $\mathrm{Ca}^{2+}$ currents is commonly observed during whole-cell patch-clamp recordings, and is even more pronounced with excised patches. This occurs as small molecules important for maintenance of channel function are eluted from the cytoplasm. Reduction in phosphorylation of the channel protein may also be involved (Byerly and Hagiwara, 1982; Fenwick et al., 1982; Byerly and Leung, 1988; Leung et al., 1989). An explanation of a run-down is less clear in our experiments, as it occurs over time even while the cells are intact. Procedures allowing good current recordings, including the dissection and the presence of barium, may eventually damage the tissue resulting in metabolically compromised cells and subsequent rundown of the $\mathrm{Ca}^{2+}$ channel currents.

\section{References}

Augustine GJ, Charlton MP, Smith SJ (1985) Calcium action in synaptic transmitter release. J Physiol (Lond) 367:163-181.

Bean BP (1984) Nitrendipine block of cardiac calcium channels: highaffinity binding to the inactivated state. Proc Natl Acad Sci USA 81 6388-6392.

Bean BP (1985) Two kinds of calcium channels in canine atrial cells. J Gen Physiol 86:1-30.

Bean BP (1989) Classes of calcium channels in vertebrate cells. Annu Rev Physiol 51:367-384.

Brezina V, Evans CG, Weiss KR (1994) Characterization of the membrane ion currents of a model molluscan muscle, the accessory radula closer muscle of Aplysia californica. III. Depolarization-activated $\mathrm{Ca}$ current. J Neurophysiol 71:2126-2138.

Byerly L, Hagiwara S (1982) Calcium currents in internally perfused nerve cell bodies of Limnea stagnalis. J Physiol (Lond) 322:503528.

Byerly L, Leung H-T (1988) Ionic currents of Drosophila neurons in embryonic cultures. J Neurosci 8:4379-4393.
Catterall WA, Seagar MJ, Takahashi M (1988) Molecular properties of dihydropyridine-sensitive calcium channels in skeletal muscle. J Biol Chem 263:3535-3538.

Cognard C, Lazdunski M, Romey G (1986) Different types of calcium channels in mammalian skeletal muscle cells in culture. Proc Natl Acad Sci USA 83:517-521.

Dascal N, Lotan I, Karni E, Gigi A (1992) Calcium channel currents in Xenopus oocytes injected with rat skeletal muscle RNA. J Physiol (Lond) 450:469-490.

DeCoursey TE, Chandy KG, Gupta S, Cahalan MD (1985) Voltagedependent ion channels in T-lymphocytes. J Neuroimmunol 10:7195.

Fenwick EM, Marty A, Neher E (1982) Sodium and calcium channels in bovine chromaffin cells. J Physiol (Lond) 331:599-635.

Fox AP, Nowycky MC, Tsien RW (1987) Kinetic and pharmacological properties distinguishing three types of calcium currents in chick sensory neurones. J Physiol (Lond) 394:149-172.

Garcia J, McKinley K, Appel SH, Stefani E (1992) Calcium current and charge movement in adult single human skeletal muscle fibers. J Physiol (Lond) 454:183-196.

Gho M, Mallart A (1986) Two distinct calcium activated $\mathrm{K}^{+}$currents in larval muscle fibers of Drosophila. Pfluegers Arch 407:526-533.

Gilly WF, Scheuer T (1993) Voltage-dependent calcium and potassium conductances in striated muscle fibers from the scorpion, Centruroides sculpturatus. J Membr Biol 134:155-167.

Glossmann H, Striessnig J (1990) Molecular properties of calcium channels. Rev Physiol Biochem Pharmacol 114:1-106.

Greenberg RM, Striessnig J, Koza A, Devay P, Glossmann H, Hall LM (1989) Native and detergent-solubilized membrane extracts from Drosophila heads contain binding sites for phenylalkylamine calcium channel blockers. Insect Biochem 19:309-322.

Hess P, Lansman JB, Tsien RW (1984) Different modes of calcium channel gating behavior favoured by dihydropyridine calcium agonists and antagonists. Nature 311:538-544.

Hille B (1977) Local anesthetics: hydrophilic and hydrophobic pathways for drug-receptor interaction. J Gen Physiol 69:497-515.

Hille B (1992) Ionic channels of excitable membranes, 2nd Ed. Sunderland, MA: Sinauer.

Hirano Y, Fozzard HA, January CT (1989) Characteristics of L-type and T-type calcium currents in canine-cardiac-Purkinje cells. Am J Physiol 256:H1478-H1492.

Hosey MM, Lazdunski M (1988) Calcium channels: molecular pharmacology, structure and regulation. J Memb Biol 104:81-105.

Jan L, Jan Y (1976) Properties of the larval neuromuscular junction in Drosophila melanogaster. J Physiol (Lond) 262:189-214.

Kokubun S, Prod'hom B, Bccker C, Porzig H, Reutcr H (1986) Studics on calcium channels in intact cardiac cells: voltage-dependent effects and cooperative interactions of dihydropyridine enantiomers. Mol Pharmacol 30:571-584.

Lee KS, Tsien RW (1983) Mechanism of calcium channel blockade by verapamil, D600, diltiazem and nitrendipine in single dialysed heart cells. Nature 302:790-794.

Leung H-T, Byerly L (1991) Characterization of single calcium channels in Drosophila embryonic nerve and muscle cells. J Neurosci 11: 3047-3059.

Leung H-T, Branton WD, Phillips HS, Jan LY, Byerly L (1989) Spider toxins selectively block calcium currents in Drosophila. Neuron 3:767-772.

Llinas R, Sugimori M, Lin J-W, Cherksey B (1989) Blocking and isolation of a calcium channel from neurons in mammals and cephalopods utilizing a toxin fraction (FTX) from funnel-web spider poison. Proc Natl Acad Sci USA 86:1689-1693.

McCleskey EW, Fox AP, Feldman DH, Cruz LJ, Olivera BM, Tsien RW, Yoshikami D (1987) $\omega$-Conotoxin: direct and persistent blockade of specific types of calcium channels in neurons but not muscle. Proc Natl Acad Sci USA 84:4327-4331.

Neuhaus R, Rosenthal R, Lütgau HC (1990) The effects of dihydropyridine derivatives on force and calcium current in frog skeletal muscle fibers. J Physiol (Lond) 427:187-209.

Nilius B, Hess P, Lansman JB, Tsien RW (1985) A novel type of calcium channel in ventricular heart cells. Nature 316:443-446.

Palade PT, Almers W (1985) Slow calcium and potassium currents in frog skeletal muscle: their relationship and pharmacologic properties. Pfluegers Arch 405:91-101.

Pauron D, Qar J, Barhanin J, Fournier D, Cuany A, Pralavorio M, Berge 
IR, I azdunski M (1987) Identification and affinity labeling of very high affinity binding sites for the phenylalkylamine series of calcium channel blockers in the Drosophila nervous system. Biochemistry 26: 63116315.

Pelzer S, Barhanin J, Pauron D, Trautwein W, Lazdunski M, Pelzer D (1989) Diversity and novel pharmacological properties of calcium channels in Drosophila brain membranes. EMBO J 8:2365-2371.

Pichon Y, Ashcroft FM (1985) Nerve and muscle: electrical activity. In: Comprehensive insect physiology, biochemistry and pharmacology (Kerkut GA, Gilbert LL, eds), pp 85-114. New York: Pergamon.

Salkoff LB, Wyman RJ (1983) Ion currents in Drosophila flight muscles. J Physiol (Lond) 337:687-709.

Sanguinetti MC, Kass RS (1984) Voltage-dependent block of calcium channel current in the calf Purkinje fiber by DHP calcium channel antagonists. Circ Res 55:336-348.

Singh S, Wu C-F (1989) Complete separation of four potassium currents in Drosophila. Neuron 2:1325-1329.

Singh S, Wu C-F (1990) Properties of potassium currents and thcir rolc in membrane excitability in Drosophila larval muscle fibers. J Exp Biol 152:59-76.

Strong JA, Fox AP, Tsien RW, Kaczmarek LK (1987) Stimulation of PKC recruits covert calcium channels in Aplysia bag cell neurons. Nature 325:714-717

Tang CM, Presser F, Morad M (1988) Amiloride selectively blocks the low threshold (T) calcium channel. Science 240:213-215.
Triggle DJ (1990) Calcium, calcium channels and calcium channel antagonists. Can J Physiol Pharmacol 68:1474-1481.

Tsien RW, Lipscombe D, Madison DV, Bley KR, Fox AP (1988) Multiple types of ncuronal calcium channcls and their selective modulation. Trends Neurosci 11:431-438.

Tytgat J, Vereecke J, Carmeliet E (1988) Differential effects of verapamil and flunarizine on cardiac L-type and T-type calcium channels. Naunyn-Schmiedeberg's Arch Pharmacol 337:690-692.

Tytgat J, Vereecke J, Carmeliet E (1990) Mechanism of cardiac T-type channel blockade by amiloride. J Pharmacol Exp Ther 254:546-551.

Uehara A, Hume JR (1985) Interactions of organic calcium channel antagonists with calcium channels in single frog atrial cells. J Gen Physiol 85:621-647

Wei XY, Rutledge A, Zhong Q, Ferrante J, Triggle DJ (1989) Calcium channels in chick neural retinal cells characterized by 1,4-DHP antagonists and activators. Can J Physiol Pharmacol 67:506-514.

Wu C-F, Haugland F (1985) Voltage-clamp analysis of membrane currents in larval muscle fibers of Drosophila: alteration of $\mathrm{K}^{+}$currents in Sh mutants. J Neurosci 5:2626-2640.

Yamoah EN, Crow T (1994) Two components of calcium currents in the soma of photoreceptors of Hermissenda. $\mathbf{J}$ Neurophysiol 72: $1327-1336$.

Yatani A, Seidel CL, Allen J, Brown AM (1987) Whole-cell and single channel calcium currents of isolated smooth muscle cells from saphenous vein. Circ Res 60:523-553. 